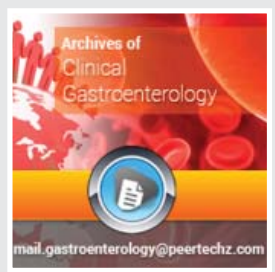

\title{
Archives of Clinical Gastroenterology
}

Thomas Marcel Mbar Wade ${ }^{1 *}$, Linda Bentefouet ${ }^{1}$, Papa Abdoulaye Ba', Mohamed Lamine Diao', Adama Berthe $^{1}$ and Ibrahima Konaté ${ }^{2}$

'Faculty of Health Sciences of the University of Thies, Thies, Senegal

2Department of General Surgery of Gaston Berger University of St Louis, St Louis, Senegal

Received: 06 February, 2018

Accepted: 21 February, 2018

Published: 22 February, 2018

*Corresponding authors: Thomas Marcel Mbar Wade, MD, Faculty of Health Sciences of the University of Thies, 10e RIAOM, BP: 83 Thies RP, Thies, Senegal, E-mail: mbarwade@hotmail.com

Keywords: Follicular lymphoma; Jejunum; Perforation https://www.peertechz.com

\section{Case Report}

\section{A case Report of Perforated Primary Follicular Lymphoma of the Jejunum presenting as Aneurismal Form}

\section{Abstract}

Primary Gastrointestinal Follicular Lymphoma is very rare. It is considered as an indolent lymphoma, but a complication such as a perforation can increase the morbidity and mortality. We report the case of a 57-years-old man who had a perforation primary follicular lymphoma of the jejunum presenting as aneurismal form. He had peritonitis at his admission, and his abdominal CT revealed a massive pneumoperitoneum and a segmental dilatation of the small intestine. The surgical exploration found a segmental dilatation of the jejunum perforated on its ante-mesenteric side with a large mesenteric lymphadenopathy. Histological and immunohistochimical of the samples shown a jejunal follicular lymphoma. The patient died of heart failure 6 months after his surgery before he has started his chemotherapy. There is no consensus for the treatment of gastrointestinal follicular lymphoma, but chemotherapy is the most common strategy. Surgery is performed for a complication such as a perforation. A complication of a gastrointestinal follicular lymphoma contributes to increase the mortality.

\section{Introduction}

The gastrointestinal tract is the most common site of extra-nodal non-Hodgkin's lymphomas (NHL), and B-cell lymphomas are the most frequent [1]. The latest World Health Organization classification of lymphoid neoplasms recognizes many subtypes of B-Cell lymphomas among which follicular lymphoma (FL) [2]. Primary gastrointestinal follicular lymphoma (GI-FL) is very rare and is considered as an indolent B-cell lymphoma. It is mostly asymptomatic, and often diagnosed during a complication such as a perforation. The perforation of GI-FL is unusual but increases significantly the morbidity and mortality. We report a case of perforated primary jejunal follicular lymphoma presented with an aneurismal appearance.

\section{Case Report}

A 57-year-old man was received in the Emergency room of Thies Regional Hospital, Senegal, in November 2015 with abdominal pain for 3 days associated with fever. He had a history of intermittent abdominal pain and loss of weight for several months. From his medical story, he is hypertensive with inconsistent treatment. He is non-diabetic, HIV negative and HbsAg negative. On physical examination, his temperature was $38.8{ }^{\circ} \mathrm{C}$ and his blood pressure was $150 / 100 \mathrm{mmHg}$. Abdominal examination revealed a painful distended abdomen.
No mass was palpable. Laboratory tests showed a high white blood cell count at $12.800 \mathrm{E} 3 / \mathrm{uL}$ and anemia at $9.2 \mathrm{~g} / \mathrm{dl}$. Abdominal Computed Tomography (CT) revealed a massive pneumoperitoneum, ascites and a segmental dilatation of the jejunum (Figure 1). The patient was admitted in the operating room, and laparotomy was done with midline incision. About 5 liters of reactive fluid were sucked. A segmental dilatation of the jejunum was found at $50 \mathrm{~cm}$ from the ligament of Treitz with a perforation on its ante-mesenteric side (Figure 2). There was also a large mesenteric lymphadenopathy with an infiltration of the mesentery (Figure 3). The other segments of gastrointestinal tract, the liver and the spleen were normal. An intestinal resection was not technically feasible due to the

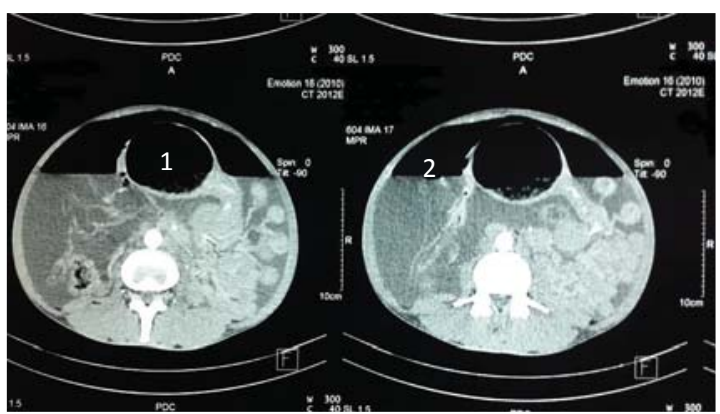

Figure 1: Abdominal Computer Tomography (CT) shows a segmental dilatation of the small intestine (1) and a massive pneumoperitoneum (2). 
extension of the infiltration through the intestine and the mesentery and the presence of a large lymphadenopathy. We instead performed a resection of the perforation margins, then a jejunal suture and intraperitoneal washout. A biopsy of the lymphadenopathy was also done, and the samples sent to the laboratory for histologic study. Post-surgery, the patient suffered a heart failure with dyspnea and edema of legs. A medical treatment was introduced by cardiologists. The intestinal transit had gradually resumed, and the operative wound was normal. The patient was discharged after 26 days from his admission.

Histological examination of the samples showed a diffuse proliferation made of small lymphocytic cells with mild to moderate nucleo-cytoplasmic atypia, and many mitosis. The stroma was scarce, and fibrous (Figure 4). This was compatible with non-Hodgkin's lymphoma of the small bowel. The

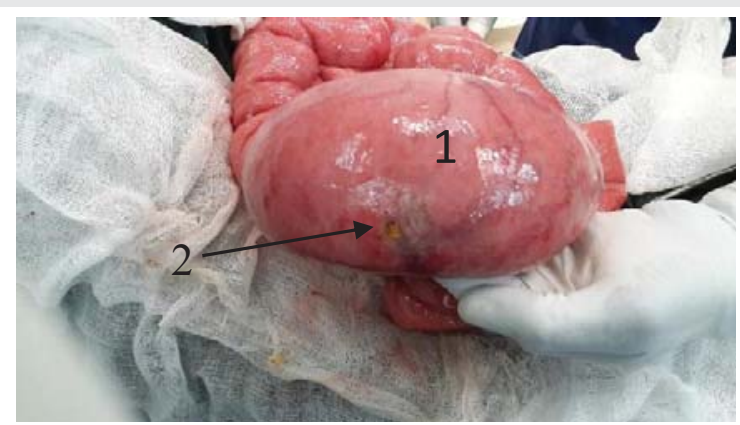

Figure 2: Surgical exploration has allowed to discover an aneurismal dilatation of the jejunum (1) with a perforation on the ante-mesenteric side (2).

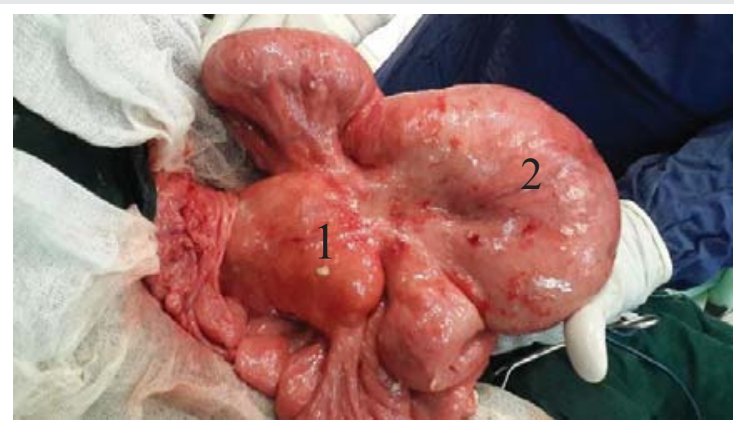

Figure 3: Surgical explorations findings: a large mesenteric lymphadenopathy with an infiltration of the mesentery (1) and an aneurismal dilatation of the jejunum (2).

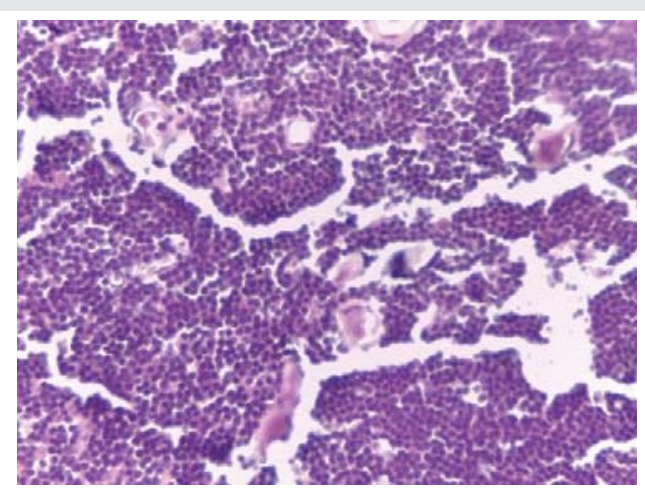

Figure 4: The microscopic findings: a proliferation of small lymphocytic cells with mild to moderate nucleo-cytoplasmic atypia, a scarce and fibrous stroma. The cells were CD20+ and CD3-. immunohistochemical analysis revealed that tumor cells were positive for $\mathrm{CD} 20$ and negative for $\mathrm{CD} 3$. Based on the findings, the diagnosis of stage II X, E primary follicular lymphoma of the jejunum was made.

The patient was followed by cardiologists and has been seen in surgery at 1 and 3 months from his discharged. He died of heart failure 6 months after his surgery before he has started his chemotherapy.

\section{Discussion}

The gastrointestinal tract is the most common site of primary extra-nodal non-Hodgkin's Lymphoma [3]. Usually it's 9+B-cell lymphoma, and the diffuse large B-cell lymphoma (DLBCL) is the most frequent. Follicular lymphoma is the second most common subtype of B-cell lymphoma $[2,4]$. Primary GI- FL without peripherical lymphadenopathy is very rare. Its incidence is estimated at $1-6 \%$ of all gastrointestinal NHL [4-6]. However, more cases have been reported in the literature in the last decades. It's why some authors argue that the incidence of GI-FL is higher [3,4]. The small intestine is the most involved site of GI-FL. Studies show that small intestine is involved in 64 to $94 \%$ of cases [5]. Contrary to Lebrun and al [7] who found a special predilection of GI-FL in the terminal ileum, most of the latest GI-FL reported affected the duodenum $[4,6,8]$. But in many studies, small intestine follicular lymphomas have a predominantly multifocal nature. It is estimated that $70 \%$ of patients with GI-FL have multiple lesions along the gastrointestinal tract $[4,6]$. Indeed, most of the primary GI-FL patients had disease localized to the small intestine, but the disease can be present in the other parts of the GI tract such as the stomach or the colon $[3,8]$. According to Damaj [1], the high frequency of small intestine involvement is probably related to the relative abundance of normal lymphoid follicles in this region. Our patient had a local infiltration with a large mesenteric lymphadenopathy, and we did not find an involvement of another site in the gastrointestinal tract or spleen, or liver. However, we did not do a bone biopsy, and we could not do an endoscopy to research another location in the gastrointestinal tract because we do not have the proper equipment.

Risk factors like HIV infection, Helicobacter pylori infection or B hepatitis have been found for DLBCL. But, for GI-FL, specific risk factors have not yet been reported [8]. A female predominance is observed in the literature, and mostly, the disease occurs after 55 years [3-5]. The disease is asymptomatic in many of the cases. The diagnosis is mostly done accidently during investigations for another disease or during a complication such as a perforation, bleeding or occlusion. Clinical manifestations are not specific and can be abdominal pain or abdominal mass. Our patient was presenting with peritonitis due to a digestive perforation. Perforation can also be a complication of chemotherapy, and mostly occurs in males [9]. The macroscopic appearance of primary gastrointestinal tract lymphomas is classically polypoid, ulceronodular and infiltrative forms [10]. The aneurismal form is a rare and specific feature of small intestine [11]. However, the macroscopic form does not predict the histological form. Indeed, the diagnosis requires a histological and immunohistochimical study. Our 
patient had a perforated aneurismal form, and the diagnosis was done after immunohistochimical study.

GI-FL is classified as an indolent lymphoma, but its longterm clinical outcome is unclear [6]. At the time of diagnosis, most patients with GI-FL are in advanced stage III or IV of the Ann Arbor staging system. Only 5\%-10\% of patients present with early stage disease I or II [12]. Small intestine primary site seems to have longer outcomes than those of the other primary sites [4]. It can be explained by the fact that it has low tendency to disseminate [6]. A complication such as perforation can occur and increases the risk of morbidity and mortality. Higher percentage of perforation occurs in the small intestine compared with stomach or large bowel, but the risk of digestive perforation is lowest in FL compared with B-cell aggressive lymphomas or $\mathrm{T}$-cell lymphomas $[9,10,13]$. It causes multiorgan failure and delays the initiation of chemotherapy which can lead to the death of the patient $[9,13]$. The peritonitis due to the perforation of the jejunum of our patient has caused his heart failure which leads to his death.

Due to the rarity of the GI-FL, there is no consensus for the treatment of the disease. Four global therapeutic strategies have been used by the authors: watch and wait attitude, radiation therapy, chemotherapy with or without radiation and surgery $[1,8]$. Surgery is essentially indicated in case of complication such as perforation. It mostly consists of intestinal resection and end to end anastomosis. This was not technically feasible for our patient because of the infiltration through the intestine and the mesentery and the presence of a large lymphadenopathy. If we performed a resection, it would not be possible to do the anastomosis. Some authors think that surgery could be done before chemotherapy in early stage of a gastrointestinal lymphoma [9]. However, this attitude is controversial for GI-FL due to the high frequency of involvement of multiple subsites. Chemotherapy is the most common attitude in the literature.

\section{Conclusion}

GI-FL is very rare. The diagnosis is mostly done during investigations for another disease or during a complication such as a perforation. The disease mostly involves the small intestine, and the duodenum is the most frequent site. GIFL is classified as an indolent lymphoma, and a perforation is unusual. But the perforation of a GI-FL is serious and contributes significantly to increase the mortality of the disease.

\section{Reference}

1. Damaj G, Verkarre V, Delmer A, Solal-Celigny P, Yakoub-Agha I, et al. (2003) Primary follicular lymphoma of the gastrointestinal tract: a study of 25 cases and a literature review. Ann Oncol 14: 623-629. Link: https://goo.gl/LJqYMm

2. Swerdlow SH, Campo E, Pileri SA, Harris NL, Stein H, et al. (2016) The 2016 revision of the World Health Organization classification of lymphoid neoplasms. Blood 127: 2375-2390. Link: https://goo.gl/aUYir2

3. Jain VK, Bystricky B, Wotherspoon AC, Chau I, Cunningham D (2012) Primary Follicular Lymphoma of the GI tract: An Increasingly Recognized Entity. J Clin Oncol 30: e370-e372. Link: https://goo.gl/66wpkx

4. Chouhan J, Batra S, Gupta R, Guha S (2016) Gastrointestinal follicular lymphoma: using primary site as a predictor of survival. Cancer Med 5: 26692677. Link: https://goo.gl/vhbsFL

5. Yamamoto S, Nakase H, Yamashita K, Matsuura M, Takada M, et al. (2010) Gastrointestinal follicular lymphoma: review of the literature. J Gastroenterol 45: 370 - 388. Link: https://goo.gl/VNwJZn

6. Bende RJ, Smit LA, Bossenbroek JG, Aarts WM, Spaargaren M, et al. (2003) Primary Follicular Lymphoma of the Small Intestine. a4ß7 Expression and Immunoglobulin ConFigureuration Suggest an Origin from Local AntigenExperienced B Cells. Am J Path 162: 105-113. Link: https://goo.gl/ioWqk1

7. LeBrun DP, Kamel OW, Cleary ML, Dorfman RF, Warnke RA (1992) Follicula Lymphomas of the Gastrointestinal Tract Pathologic Features in 31 Cases and bcl-2 Oncogenic Protein Expression. Am J Path 140: 1327-1335. Link: https://goo.gl/6rntkb

8. Graham RL, Mardones MA, Krause JR (2015) Primary follicular lymphoma of the duodenum. Proc (Bayl Univ Med Cent) 28: 381-383. Link: https://goo.gl/92wJnC

9. Vaidya R, Habermann TM, Donohue JH, Ristow KM, Maurer MJ, et al. (2013) Bowel perforation in intestinal lymphoma: incidence and clinical features. Ann Oncol 24: 2439-2443. Link: https://goo.gl/drvxHH

10. Rehaman SA, Ramachandra CS, Jackaya RP (2016). Primary Gastro Intestinal Lymphoma Presenting as Perforation Peritonitis. J Clin Diag Res 10(3): PD22-PD24. Link: https://goo.gl/CGyEg2

11. Jouret A, Haot J (1998) Primary digestive lymphomas: macroscopic presentation. Acta Endoscopica 28: 495-502. Link: https://goo.gl/EszbFr

12. Iwamuro M, Kondo E, Takata K, Yoshino T, Okada H (2016) Diagnosis of follicular lymphoma of the gastrointestinal tract: A better initial diagnostic workup. World J Gastroenterol 22: 1674-1683. Link: https://goo.gl/CpiM81

13. Chuang SS, Ye H, Yang SF, Huang WT, Chen HK, et al. (2008) Perforation predicts poor prognosis in patients with primary intestinal diffuse large B-cell lymphoma. Histopathology 53: 432-440. Link: https://goo.gl/o57WSms 